This is a self-archived version of an original article. This version may differ from the original in pagination and typographic details.

Author(s): Heiskanen, Noora; Alasuutari, Maarit; Vehkakoski, Tanja

Title: Intertextual Voices of Children, Parents, and Specialists in Individual Education Plans

Year: 2021

Version: Accepted version (Final draft)

Copyright: (c) 2019 Scandinavian Journal of Educational Research

Rights: In Copyright

Rights url: http://rightsstatements.org/page/InC/1.0/?language=en

Please cite the original version:

Heiskanen, N., Alasuutari, M., \& Vehkakoski, T. (2021). Intertextual Voices of Children, Parents, and Specialists in Individual Education Plans. Scandinavian Journal of Educational Research, 65(1), 36-53. https://doi.org/10.1080/00313831.2019.1650825 


\title{
Intertextual Voices of Children, Parents, and Specialists in Individual Education Plans
}

\begin{abstract}
Planning support and education services requires multifaceted information from professionals, parents, and children. Despite this, educators have emphasized professional opinions in individual education plans (IEPs), whereas the perspectives of children and parents have remained inconsequential. In this study, we examine the intertextual voices of children, parents, and specialists in IEPs $(\mathrm{N}=287)$ drafted in Finnish early childhood education and care (ECEC). The findings show that educators use intertextual voices to serve the following functions: 1) Creating a more multidimensional image of a child, 2) presenting evidence for their argumentation, and 3) assigning the responsibility to others. Consequently, the children, parents, and specialists were positioned as either speakers without influence, legitimators of educator's knowledge, or powerful decision-makers. Keywords: individual education plan (IEP); early childhood education and care (ECEC); intertextuality; voice
\end{abstract}




\section{Introduction}

The planning of early childhood education and care (ECEC) should be a team decisionmaking process which is based on the multifaceted information of children's strengths, interests, needs, and viewpoints (Sandall, McLean, \& Smith, 2000; see also Trivette \& Dunst, 2000). Participation of children, parents, and specialists (e.g., medical professionals, therapists, and psychologists) offers educators a holistic view to planning, which is of particular importance for children who are identified as having special educational needs (SEN; see, e.g., Bayat, Mindes, \& Covitt, 2010; Forbes, 2008; Goepel, 2009; Karila, 2006; Karlsdottir \& Garoarsdottir, 2010; Røn Larsen, 2016; Trivette \& Dunst, 2000). The importance of participation and multi-voiced planning is often justified for two reasons. First, children's right to participate is presented as an absolute value of an educational system and a society (see Raby, 2014). Second, the active participation of children and parents in planning has been found to have positive effects for a child. For example, parental participation is suggested to have an influence on a child's achievement in school, when the achievements of older children are studied (e.g., Sebastian, Moon, \& Cummingham, 2017). In addition, a positive association is reported between students' IEP participation, their knowledge about their IEPs (Royer, 2017), and their academic outcomes (e.g., Barnard-Brak \& Lechtenberger, 2009).

In this study, we examine how the voices of children, parents, and specialists are included in the IEPs drafted in Finnish ECEC. Here, IEP is used as an umbrella concept to cover all individual plans that are drafted for children, according to Finnish legislation and curricula. These plans include ECEC plans and preprimary education plans as well as plans specifically aimed at planning the support for children who are identified as having SEN (i.e., plans for intensified support and individual education plans). In practice, the process of drafting IEPs is typically actualized through pre-organized meetings among children, 
parents, early childhood educators, and, as needed, specialists. Thus, IEPs are considered practical tools to enhance the involvement of children and parents (e.g. Alasuutari, Markström, \& Vallberg-Roth, 2014; Buldu, 2010).

We examine the participation of children, parents, and specialists through the concept of intertextual voices. We are especially interested in whether and how the knowledge of children, parents, and specialists is presented and utilized and thus, how they become epistemically positioned in the IEPs. Following Bednarek (2006), epistemic positioning can be defined as "the expression of assessments concerning knowledge" (p. 635), which illustrates, for example, the basis and (un)certainty of a piece of intertextual information ( $\mathrm{p}$. 638). Then, one's epistemic position in a particular situation can be seen as a socially constructed entitlement of being considered a (in)valid informant and possessor of (in)accurate knowledge. Examining epistemic positioning is of great importance since in addition to being included in an IEP, the voices of children and parents should also be influential and utilized in planning. In previous research, the focus has typically been either on the children's (e.g., Paananen \& Lipponen, 2016) or the parents' participation (e.g., Karila \& Alasuutari, 2012; Zeitlin \& Curcic, 2014) separately. Investigations of multiple voices, including also specialists, have been less frequent, although educators' practices to include these voices in educational planning are important for successful participation (Keyes, 2002).

\section{The Concept of Participation}

Participation is fundamentally interlinked with power relations. In the broadest sense, participation can be understood as a free space to have a voice (see Horgan et al., 2017). Then, participation is enabled by hearing different voices and renouncing dominance, thereby fostering more powerful engagement and democratic practices (Gallagher, 2008). 
However, participation is not only about seeking views; it also about sharing some influential power with others (Hill, Davis, Prout \& Tisdall, 2004; Shier, 2001; Sinclair, 2004). Consequently, participation can be understood as a form of institutional governance, following Foucauldian thinking. According to Foucault, power is understood as something that people do in social relations, not something that a particular person or institution automatically possesses (Gallagher, 2008). Thus, participation is not only about giving away some of one's power or empowering others, it is also about a relationship between individuals (Gallagher, 2008). Therefore, the starting point for investigating participation should focus on the relational nature of power as a collective act (Gallagher, 2008; see also Raby, 2014). This starting point should lead researchers to study the relationships in which power is exercised as well as the specific techniques of governance in participative initiatives (Gallagher, 2008).

Even though participation is emphasized, in all the institutions related to children's lives, the participation of especially the youngest children (Lansdown, 2005) and their chances to influence through participation (Thomas, 2007) seem to remain marginal. The same kind of idea is presented in studies investigating parental participation framed by the concept of educational partnership (e.g. Goepel, 2009; Hodge \& Runswick-Cole, 2008; Karila \& Alasuutari, 2012). These studies state that even though partnership is emphasized, relationships between parents and educators appear unequal, and parent's influential power is weak.

In Hart's (1992) eight-step ladders of participation and Shier's (2001) five-stage model, the level of participation increases, starting with mainly listening to others and eventually reaching the consequential sharing of power and responsibility. Shier (2001) states that in order to achieve participation, the adults working with children, procedural arrangements, 
and policy-level structures need to enable and support the active and powerful role of children. Hart (1992) defines non-participation as a situation where adults use children to implement their own wishes, to run adult-led initiatives, or to reserve all the influential power for themselves. In the context of drafting a child's IEP, Goepel (2009) observes that “'Having a say' is about the child being empowered and engaging much more fully than in the giving of allegiance to well-intentioned but predetermined targets" (p. 131). Similarly, in Epstein's (1995) framework for six types of parental involvement, which includes parenting, communicating, volunteering, contributing to children's learning at home, decision making, and collaborating with community, the power to participate in a meaningful way becomes emphasized.

\section{Examining Intertextual Voices}

In this study, we approach participation especially in terms of power and knowing in a specific pedagogical practice, an IEP. We investigate the intertextuality in IEPs, an analytical concept that follows the discourse analytic tradition (see, e.g., Fairclough, 1992a, 1992b; Kamberelis \& Scott, 1992; Linell, 1998). This is due to our understanding of IEPs as essentially intertextual: they are written, based on discussions with parents and specialists, and rooted in the institutional practices of writing (see also Günther, Raitakari \& Juhila, 2015; Ravotas \& Berkenkotter, 1998). In addition to education, intertextuality in documents have been studied in many professional fields, such as psychiatry and therapy (e.g., Ravotas \& Berkenkotter, 1998), criminal law (e.g. Komter, 2006), mental health care and social work (e.g. Günther et al., 2015), and pediatrics (e.g., Kelle, Seehaus \& Bollig, 2015; Schryer, Bell, Mian, Sparrord \& Lingard, 2011).

Considering intertextuality, we apply the concept of intertextual voices to refer to the expression of different viewpoints in IEPs. An intertextual voice in a text represents a 
perspective of someone other than the author, which the author has taken from one context (e.g., a discussion with a parent or a statement of a medical professional) and referred, cited, or otherwise borrowed in an IEP (see Fairclough, 2003; Linell, 1998). In some studies, the same kinds of expressed voices are approached by using the concept of reported speech (see, e.g., Mayes, 1990). Intertextuality and multiple voices can be seen as inevitable parts of using language and creating texts. Kamberelis and Scott (1992) refer to Bakhtin (1981) when they say that constructing a text is always a process of responses to and further development of pre-existing discourses. Therefore, a text always relies on what was previously said and written (see also Kamberelis \& Scott, 1992). Even though intertextuality can be seen as a fundamental part of constructing texts, the use of intertextual voices is not coincidental but the author's choice (e.g., Clark \& Gerrig, 1990). The use of a voice from someone other than the author can have multiple functions, from justifying a professional opinion to dramatizing events (Ravotas \& Berkenkotter, 1998). Therefore, intertextual voices are always socially constructed, and they can be used differently on different occasions (see also Komulainen, 2007).

Expressing voices in texts can take many forms. Voices can be expressed as completely separate; they can be partly merged and partly independent; they can even be contradictory or merged entirely into a double-voiced text (Bakhtin, 1981). Therefore, intertextuality can be a great source of ambivalence (Fairclough, 1992a), as various types of mixing, blending, and blurring different voices are often found (Linell, 1998). As recontextualizing discourse is a process of meaning-making, the relations and proportions of things may change when texts are cited (Linell, 1998). A writer can, for example, deny, confirm, or adopt the viewpoint of an intertextual voice as well as maintain an objective, negative, amused, or positive stance toward it (Aikhenvald, 2007; Bakhtin, 1981; Fairclough, 
1992a). Moreover, voices can be discriminated against, subdued, highlighted, or even silenced as well as endorsed and/or re-perspectivized (Linell, 1998).

\section{Previous Research on Intertextuality in IEPs}

Previous research has shown strong and consistent professional dominance in practices related to the drafting of IEPs (see, e.g., Blackwell \& Rossetti, 2014; Goepel, 2009; Isaksson, 2007). In this process, children are typically positioned as objects of documentation rather than participants in it (Markström, 2015). In a study of children's participation in IEPs drafted in Finnish ECEC, Paananen and Lipponen (2016) found that educators only referred to the views of a child in 23 out of 380 documented agreements between parents and educators. Moreover, in only seven agreements could children's voice be considered influential. Paananen and Lipponen (2016) also perceived that children typically had a say on issues that did not collide with pre-existing rules and practices and that were directly connected to them, such as playing (see also Elfström Pettersson, 2015; Gallagher, 2008). This was most visible concerning children who are identified as having SEN, who often had the power to support pre-existing arrangements but not the power to initiate constitutive changes in practices (Paananen \& Lipponen, 2016). Internationally, children's everyday life experiences and knowledge are also often overshadowed or positioned as anecdotal in educational decision-making (Røn Larsen, 2016; see also Ravotas \& Berkenkotter, 1998).

The same kinds of restrictions have also been found with parental participation (see Blackwell \& Rossetti, 2014; Isaksson, 2007; Karila \& Alasuutari, 2012), which is described by Skrtic (2005) as often more symbolic than meaningful. Blackwell and Rossetti (2014) verbalize the predominant situation in the context of IEPs as one in which 
professionals "exert considerable control over the direction of IEP meetings and content, while families are frequently passive participants" (p. 11).

Although some studies have shown that parents are predominantly satisfied with the IEP process (see, e.g., Fish, 2008), research has mainly reported parental dissatisfaction, especially among parents with a high socioeconomic status (Reiman, Beck, Coppola, \& Engiles, 2010; Slade, Eisenhower, Carter, \& Blacher, 2018; see also Rosetti et al., 2018). Moreover, culturally and linguistically diverse families face barriers to participation (e.g. Pang, 2011; Rossetti et al., 2018). In general, in a study by Zeitlin and Curcic (2014), parents did not see IEPs as communication or partnership tools but as professionally led tools for problematizing children’s situation (see also Røn Larsen, 2016, p. 86). Moreover, parents did not think that IEPs focused on the right things, found them difficult to understand as well as objectifying from the child's perspective (Zeitlin \& Curcic, 2014).

Discussions that precede the drafting of children's IEPs are seen as a fundamental part of especially hearing parental voices. Ideally, these discussions are democratic conversations where parents, educators, and specialists raise their views (Warren, 2017). However, it has been found that parents sometimes hold back their viewpoints during the discussions (Martin, Huber Marshall, \& Sale, 2004; Ruppar \& Gaffney, 2011), and even when they express their views, they lack opportunities to contribute to significant aspects of planning (Hodge \& Runswick-Cole, 2008; Karila \& Alasuutari, 2012; Zeitlin \& Curcic, 2014). Karila and Alasuutari (2012) conclude that this sets educational and pedagogical practices "outside the sphere of parental involvement and educational partnership" (p. 22). Consequently, even though the intertextual voices of children and parents can be found in documents, the impact of these perspectives on pedagogical work is not self-evident as 
educators have power over ECEC practices (see, e.g., Paananen \& Lipponen, 2016; Thomas, 2007).

Contrary to the situation of children and parents, specialists seem to have a strong position in having their voices heard. This is somewhat predictable as specialists' disciplinespecific knowledge serve as an important resource for educators when they plan education for children who are identified as having SEN (see also Forbes, 2008). According to previous research, compared with general educators, specialized professionals voice their ideas more often during discussions related to drafting IEPs (Martin et al., 2004; Ruppar \& Gaffney, 2011), and general educators consider their role important (Arivett, Rust, Brissie, \& Dansby, 2007). Especially in the case of children who are identified as having SEN, the viewpoints of a large variety of specialists are often utilized in planning (Barnes \& Turner, 2001; Daniels, 2006; Kovanen, 2002).

\section{This Study and Research Questions}

To conclude, children's and parents' roles seem to be weak when IEPs are drafted, and their voices seldom influence agreements or decisions on pedagogical practices. It has also been stated that some children (e.g., children identified as having SEN) would have less possibilities to participate than others (e.g., children without SEN). However, one key aim of drafting IEPs is to involve the children and the parents in meaningful ways that will enable full, consequential participation. Therefore, in this study, we are interested in how children, parents, and specialists are described as informants and participants in IEPs in relation to the pedagogical decision-making process. We aim to answer the following research questions: 
1) How are the voices of children, parents, and specialists linguistically presented in IEPs?

2) What functions do these intertextual voices serve in the IEPs?

3) How are the intertextual voices of children, parents, and specialists epistemically positioned in the IEPs?

\section{The Method}

\section{The IEP Process in Finnish ECEC}

Finnish ECEC covers services for children up to approximately seven years of age and includes preprimary education in the year preceding compulsory comprehensive school. In practice, all Finnish children has an IEP in ECEC even though the names of these documents vary. Since 2004, in the Finnish core curriculum for ECEC (NRDCWH, 2003), drafting an IEP document called an ECEC plan for every child has been advised, and since the 2015 legislative reform, this has been mandatory (Early Childhood Education Act 540/2018). Moreover, in preprimary education, a preprimary education plan is drafted for most six-year-olds, including all children who are identified as having SEN (Basic Education Act, 628/1998). This document can be replaced with support-centered documents when a child's need for support is more long-term or extensive. In the Finnish context, these support-centered documents are called plans for intensified support (Basic Education Act 628/1998) and individual education plans (Basic Education Act 628/1998).

The legislation and curricula for ECEC in Finland describe cooperation with children's parents as a starting point of ECEC and the children's participation as one of the key aims and operational principles of early education (Basic Education Act 628/1998; Early Childhood Education Act 540/2018; FNBE, 2016, 2017). The Finnish National Core 
Curricula for ECEC (FNBE, 2017) and preprimary education (FNBE, 2016) explicitly underline the importance of all children's and parents' participation in compiling IEPs and planning children's education. Regarding ECEC (FNBE, 2017), the following instructions are given:

The personnel prepare the plan in collaboration with the child's guardians. The child's opinions and wishes must be heard and taken into account in the plan. The personnel are responsible for finding appropriate methods for determining the child's viewpoints. (p.11)

In practice, these discussions are typically arranged in ECEC centers twice a year when parents are invited to discuss and to draft an IEP with a teacher or other staff member (FNBE, 2017). In addition, daily discussions with parents are encouraged. For younger children, participation is typically ensured through interviews or daily discussions with them and at home prior to the IEP meeting. Additionally, educators can offer children opportunities to participate in IEP meetings with their parents, which is often the case in preprimary education. Moreover, children and parents have traditionally been offered the opportunity to include their own writing in the IEP, or drawing, in the case of a young child.

In addition to children and parents, cooperation with specialists is also required (Basic Education Act 628/1998; Early Childhood Education Act, 540/2018; FNBE, 2016, 2017). This is especially emphasized when a child is identified as having SEN. Support services and rehabilitation are integrated into a child's daily schedule in education (Kovanen, 2002; Rantala, Uotinen, \& McWilliam, 2009). 
In this study, we focus solely on the writings in the IEPs written by educators and do not take the writings of parents or possible drawings of children into account. We have chosen this approach because the key aim of seeking children's and parents' perspectives during the IEP process is to utilize them in planning (FNBE, 2017, p. 11). The educators are in a powerful position in the process of drafting IEPs as they write the viewpoints of children and parents as well as objectives and support measures into the documents, and even more importantly, will implement the content written in the IEPs. Therefore, during the process of planning children's education, educators act as gate-keepers (see Linell, 1998), and are able to add and omit content and to decide how voices are presented and utilized in pedagogical planning (see also Alasuutari, 2014; Røn Larsen, 2016).

\section{Research Data and Sampling}

We collected research data from 23 Finnish preprimary education classes in five municipalities during 2015-2016. The data include 287 IEPs that were drafted for 108 children within their years in ECEC and preprimary education. In this study, we included both ECEC plans and preprimary education plans as well as plans specifically aimed at planning the support for a child who is identified as having SEN (plans for intensified support and individual education plans). In this study, we call all of the studied documents IEPs. Respectively, support-centered plans are drafted only after the identification of SEN. The research data is presented in Table 1.

\section{(Insert Table 1 somewhere here, please)}

In recruiting the participating municipalities, we applied purposeful sampling (Patton, 2015), aimed at maximizing variations in the data. Finnish municipalities are very independent in terms of local regulations for IEPs; consequently, municipal differences are 
notable. Municipalities can, for example, choose the forms for the IEPS and set instructions for educational support. By choosing municipalities based on varying pedagogical practices, geographical locations, and size, we were able to include more variations in the data.

The selection of preprimary classes in each municipality was also informed by the principle of maximum variation. We asked the ECEC administrators to do the selection and instructed them to search for preprimary classes that differed as much as possible in terms of the location of the class in the municipality, the socioeconomic backgrounds of the families in the area, pedagogical practices, and other diversifying elements. As a result, the total number of preprimary classes was 23 , with a variance of one ${ }^{1}$ to 10 classes per municipality.

Finally, we applied two kinds of sampling techniques to choose participating children from the selected preprimary classes. In 10 of the classes, we asked the guardians of all children for research consent. However, as we wanted to achieve data that would purposefully overrepresent the documents of children who are identified as having SEN, in 13 classes, we only asked the guardians of children who had been identified as having SEN to give their consent. This kind of sampling can be described as group characteristics sampling (Patton, 2015). Consequently, in the research data, $27 \%$ of the children were identified as having SEN, although in Finnish ECEC, 7\% of children had been identified of having SEN in 2016 (National Institute for Health and Welfare [NIHW], 2017).

We followed the ethical guidelines for data collection (Christians, 2011) by protecting the anonymity of municipalities and the children's identities by applying pseudonymity. We

\footnotetext{
${ }^{1}$ The less-populated municipalities had only one preprimary education class.
} 
requested written research permission from the municipal authorities and written informed consent from the children's guardians. We also informed the guardians of their right to withdraw from the study at any time.

\section{Analysis}

The first phase of the analysis can be described as searching for intertextual voices as we collected all the expressions from the IEPs that indicated the presence of intertextual information. We observed key linguistic features and markers that typically indicate the presence of intertextuality (see Fairclough, 1992a; Mayes, 1990). Intertextualized expressions were either direct (e.g., Anna said, "I need help") or indirect (e.g., Anna said that she needs help) presentations of a voice (see Fairclough, 1992b, p. 274). In addition, pronoun choices, verb tenses, and words indicating a time and place of an event were observed when searching for intertextuality (Mayes, 1990).

In addition to the aforementioned explicit linguistic markers, intertextuality can also be constructed implicitly without quotations and reporting clauses and without specifically indicating the source of the information (see Linell, 1998). Schryer et al. (2011) refer to this kind of insufficiently attributed citations as incomplete or partial expressions. Consequently, while coding the intertextual expressions during the analysis, we had to elaborate our definition of intertextuality through three inclusion/exclusion criteria:

1) Explicit expressions that illustrated intertextuality through direct citations and quotation marks were included in further analysis.

2) Implicit expressions of intertextuality that did not name any specific source directly but the source could be identified from contextual information were included in further analysis. 
3) Unverbalized voices and expressions that blended multiple voices without indicating their source were excluded from further analysis.

The last type signals that multiple viewpoints might be utilized, even though the constitution of the team making this decision is left unverbalized. As we specifically wanted to investigate the voices of children, parents, and specialists, we categorized these kinds of expressions as double-voiced and omitted them from further analysis. In our data, leaving the source of unverbalized voices might be due to the Finnish convention that strives towards shared agreement between ECEC professionals and parents in the drafting of IEPs. In writing, this can lead to merging of viewpoints and voices as ECEC professionals record shared but not personified agreements to the IEPs (see Karila \& Alasuutari, 2012). In this convention, however, the voices of a children, parents, and specialists are weakened.

After utilizing the above-mentioned selection criteria, we found that in $15.3 \%$ of the studied IEPs $(\mathrm{N}=287)$ including all children with or without identified SEN, educators described children's voices in their writing. Regarding parents, the percentage was $24.4 \%$ and for specialists, $15.0 \%$. However, when the IEPs of children who had been identified of having SEN were investigated separately, a child's voice was found more often (22.2\%) as well as the voices of parents (33.3\%) and specialists (31.3\%) compared to the documents of children who were not identified of having SEN. Table 2 presents the prevalence of the inclusion of voices in the IEP-specific investigation and comparisons of these prevalences between the documents of children who are identified as having SEN and the documents of children who are not.

(Insert Table 2 somewhere here, please) 
After the first phase, we moved on to examine the typical features of intertextualizing voices. Then, we classified the expressions containing intertextual information based on the information source and investigated what kinds of linguistic features, such as subjects, nouns, and types of quoting, were unique in references to a particular voice. Next, we investigated the reasons for which educators used the intertextual references to these voices in the documents. In studying this, we applied the concept of linguistic function in relation to the use of a specific text or a section of it and its consequences: what is done with a particular text. In studying these functions, we paid attention to intertextual references of voices in a larger textual context. This included reading the entire IEPs from the point of view of what educators did with intertextuality. In studying functions, the relationship between intertextual references and educators' voices in the text turned out to be important.

Finally, we focused on if and how educators constructed children, parents, and specialists as epistemic authorities when citing intertextual voices. In analyzing epistemic positions, we investigated whose information was presented as relevant or irrelevant, how this was done, and how educators possibly brought out their own stance toward the knowledge of others. In studying the writer's stance, we observed linguistic markers of emotions, such as specific words and writing that indicated distance-taking, agreement, or a neutral stance. Finally, we studied how definitively the educators presented the information that was constructed through the use of references to the intertextual voices.

\section{Findings}

\section{Intertextual Voices: Children, Parents, and Specialists}

The explicitness of including children's, parents', and specialists' voices in the IEPs varied remarkably. The characteristic intertextual markers and linguistic features of describing 
these three voices are presented in Table 3. Next, we present how the intertextual voices are described in IEPs. All names used in the extracts are pseudonyms.

(Insert Table 3 somewhere here, please)

Child's voice. When describing children's voices, educators often use the first person structure and direct quotations in the sentences. Consequently, it seems as though the child is speaking with her or his own voice and words, as in the following extracts:

\section{Extract 1}

Oliver: "I am good at playing and swimming.

I can play ice hockey and can play games.

I can't skate backwards, I can't fly."

\section{Extract 2}

Sleeps peacefully with a toy dog under his arm and wakes up as a happy "mää helään” (I wake up $)^{2}-$ boy.

In Extract 1, Oliver's voice is presented by quoting his self-assessment word for word. Such quotations stand out from other text written with standard language, as their sentence structure is simpler and shorter. They can be seen as reproducing a child's way of speaking and are probably written while the child dictates. Extract 2 is an example of the use of socalled scare quotes, single words or short expressions in quotation marks (Fairclough, 1992a). The use of the scare quote ("mää helään" - boy) can be seen as an expression of the writer's epistemological stance toward the child's viewpoint. While it describes the child's unique way of speaking about awakening, it constructs the description as funny,

\footnotetext{
${ }^{2}$ The Finnish expression "mää herään" is a colloquialism for "I wake up.” In the extract, a child has a pronunciation error in the $r$ sound; consequently, he is unable to pronounce the expression "mää herään" properly but, instead, says "mä helään".
} 
illustrative, or exceptional. In the example, this is done especially by showing in the writing that the child is not able to pronounce the Finnish sound of $r$. This way of using scare quotes only relates to the descriptions of children's perspectives; they are not used when including the parental and specialists' voices.

In addition to the direct descriptions that allow the child's speaking to be written as such, descriptions can be interpretive when educators leave the origin of the knowledge unverbalized. In this case, the sentences refer to the child's own mental state, such as feelings, as in the following extracts.

\section{Extract 3}

Leo likes to play "workman" and to renovate places.

\section{Extract 4}

Samuel likes to cheat others.

In Extracts 3 and 4, the indirect situations leave room for interpretation: although children have the primary ownership of their likes and dislikes, the sentences do not reveal whether the source of the information is a child (i.e., a child has said it or otherwise allowed the educator to know about it) himself, or whether it is based on the educator's observationbased interpretations of Leo's and Samuel's likes. The uncertainty of how a writer has come to their conclusion is clearly noticeably in Extract 4, where a description about an unwanted behavior raises the question of whether it is really an interest of Samuel's to cheat others and how the educator has come to this conclusion. The description is written as an answer to a question that asks for an account of child's situation from an educator. 
Parental voice. When parental perspective is referred to, a writer typically takes a distant stance to it by describing the viewpoint as heard through reportative clauses and indirect quotations. In Extract 5, a reported saying of a mother is presented.

\section{Extract 5}

Benjamin is, in his mother's words, a happy, social, athletic, and sprightly boy.

In Extract 5, a mother's voice is described with an indirect quotation without quotation marks. The description seems ostensibly neutral, yet the expression 'in his mother's words" may imply the educator's distance-taking from the presented opinion. In the extract, the educator leaves the question of her or his own stance unclear by emphasizing that this fact concerns the mother's opinion. Moreover, the text after the extract continues with the educator's description about Benjamin, where she describes different matters than his mother and concentrates on his identified SEN.

As seen in Extract 5, parents are referred to by identifying their relationship with the child. Thus, they are typically referred to as "mom/mother" and "dad/father" or generically as "parent(s)." Only seldom are parents referred to by their first names, which is typical considering these are children's voices. Parental voice can also be presented by writing that "at home, the child is ...." Thus, the location is used to identify the origin of a voice. Typically, only one parental voice is presented in the documents. Most commonly, it is the mother or the parent who has participated in the parent-educator discussion preceding the drafting of the IEP. In individual cases, the voices of parents are equally presented in the document, as in Extract 6.

\section{Extract 6}


Olivia sleeps in kindergarten for about 1.5 hours. In her mother's home, she doesn't take naps anymore, but in her father's home, she sleeps.

In Extract 6, the viewpoints from both of the child's parental homes are found in the document. However, the source of the information is not presented, even though "the voices" of both parents are illustrated. Therefore, it is impossible to say whether the information is from both parents or only one parent. The IEPs analyzed in this study include many similar descriptions, which clearly indicate that the information was not provided by an educator. In addition, the extensive use of the passive voice in writing (e.g., "challenges are observed") compounds the impression and makes it difficult to assess whose information is being expressed.

Specialists' voice. The voices of specialists are often indirectly cited in the documents and only rarely reported with direct quotations. When adding intertextual information from specialists, educators typically explicitly mark the origin of the knowledge by mentioning the specialist by first and last name and title. In Extract 8, an example of reporting an occupational therapist's voice is presented.

\section{Extract 8}

Fine motor skills are, according to the occupational therapy assessment, two years behind peers. This shows in tasks in which a pencil is used (pencil grid and pencil pressing), using scissors, and manual dexterity.

In Extract 8, the occupational therapist's assessment is indirectly cited as a source of information. In the first sentence, intertextual information is reported as such, and the writer does not implicate an epistemological stance toward an intertextual voice. This is typical of specialists' voices in the documents: the writer shows no assessment of the knowledge. However, in the latter sentence, an educator supports the therapist's assessment by describing 
the manifestation of a challenge in the ECEC context and, simultaneously, displays a positive stance toward the information.

Even though the source of the information provided by a specialist is often very explicitly stated in the documents, exceptions exist. In Extract 9, an educator leaves the source of the recommendation unclear by using the passive tense in writing. Only the content of the description gives a clue that the information is intertextual, as an educator writes about the practices that have been recommended for ECEC staff to implement.

\section{Extract 9}

GraphoGame ${ }^{3}$ is recommended for strengthening and enhancing reading readiness.

\section{Linguistic Functions of Intertextual Information}

The use of intertextual voices seems to serve three functions in the documents: 1) Creating a multi-perspective image of a child's situation, 2) presenting evidence for the author's argumentation, and 3) assigning the responsibility to other parties in the decision-making process. Next, we present these functions and illustrate how the intertextual voices are positioned in relation to the voice of an educator. These findings are compiled in Table 4.

(Insert Table 4 somewhere here, please)

Creating a more multi-perspective image of a child. When the educator adds intertextual voices to an IEP, they mainly create a more multi-perspective image of a child's situation but descriptions are not otherwise exploited. Consequently, children, parents, or specialists become positioned as speakers without influence. This is most typical with children's voices. In creating multi-perspective texts, the intertextual

\footnotetext{
${ }^{3}$ GraphoGame is a free-of-charge mobile and desktop game aimed at enhancing early literacy skills.
} 
information remains detached, as it has no link to planning or decision-making in the document. Therefore, it can be understood as mainly diversifying in relation to the educator's viewpoints. In Extracts 10 and 11, examples of creating multi-perspective texts without exploiting viewpoint are presented. There, documented viewpoints of mothers are described.

Extract 10

At home, possible situations where a child refuses to cooperate are solved by discussing. Events that will happen that day are discussed in the morning. Anticipating and discussing the daily course of events eases everyday life.

\section{Extract 11}

Mother said that at home these kinds of challenges are not shown; they emerge in a big group.

In Extracts 10 and 11, mothers describe their children's situations. In both extracts, useful practices and viewpoints concerning the children's daily life are described; however, that information is not exploited or taken into consideration in the documents when planning support. This illustrates a main essence of this linguistic function of only creating multiperspective texts: mothers have had a say, which is also documented, yet it has not been consequential.

Sometimes educators describe children's challenges by using intertextual references or citations. Then, the educator hands over the responsibility of describing challenges to another party. This is the case in Extract 12, where Sebastian's speech development and challenges are described by using an intertextual reference to the information provided by a speech therapist. 


\section{Extract 12}

Sebastian has had speech therapy assessments because of his speech development, last time in autumn 2014, and he received speech therapy during the 2014 school year. The ligament under his tongue has been operated on three times, last time in 2014. There have been challenges in language development and oral motor skills during early childhood. Currently (spring 2015), at-home exercises are being given by a speech therapist. Speech therapy will continue in autumn 2015 .

Otherwise, Sebastian is a very insightful boy. He has, for example, learned to read during spring 2015.

In Extract 12, an educator describes Sebastian's challenges by using intertextual information from a speech therapist. After describing the challenges, the educator completes her writing by describing Sebastian's positive characteristics and his learning. In this part, the voice seems to be that of an educator. The description of a speech therapist's intertextual voice is not utilized later in the IEP when decisions or agreements are described.

Presenting evidence for the author's argumentation. The intertextual voices are also used in the IEP to confirm the educator's perspective by positioning another party as its legitimator. Then, the information presented is often subordinate or substitutive to the educator's viewpoint, and it is used in an instrumental manner. In Extract 13, a mother's approval of the educator's viewpoint is presented.

\section{Extract 13}

Kindergarten: Plays better alone. Also plays with others. Sometimes argues about toys and, by implication, pushes and uses violence. 
Same ideas at home.

In Extract 13, a mother's opinion is described as confirmation of the educator's observations about Anna's play-related challenges. Parental opinion is not, however, presented as such, nor does it bring anything new to the description of the situation. In this case, the use of an intertextual voice seems to serve the function of emphasizing the authority of the educator's voice.

This kind of use of an intertextual voice typically occurs when parents and specialists outside the ECEC context are cited. However, children's viewpoints or observations of their everyday life can also be used to provide confirmation of an educator's opinion. However, this use is slightly different, as children are often referred to with direct quotations within quotation marks. Here, the child's actual thoughts or viewpoints are not cited, but the citation describes the child's actions and behaviors, such as temper tantrums or pronunciation errors. Consequently, the intertextual expression is confirmative in relation to the educator's interpretation, as it illustrates the situation with everyday life examples. In Extract 14, Amelia's ways of pronouncing words are used as evidence for the educators' observations.

\section{Extract 14}

Amelia expresses herself with speech and single signs. Sentences are two- to three-word sentences. It is difficult to make out her speech. Words are duplicated easily: for example, “(What can I) eat, eat?” Recognizes colors when support signs are used. See the papers from the hospital's phoniatrics outpatient clinic.

Assigning the responsibility to others. When intertextual voices are explicitly interconnected with planning and decision-making, an intertextual voice is positioned as a 
powerful decision-maker. Then the intertextual information becomes influential or even pre-conditional to the educator's educational decisions. However, even though the information is presented as binding, the level of the binding force varies. In Extract 16, the intertextual information from Jesse's doctor has been described as binding to the educators.

\section{Extract 16}

Doctor (Anna Vaara) has started a medication for Jesse because of the clear challenges in attention and concentration. In preprimary education, observations will be made about the efficacy of the medication as well as possible side effects. Mother tells preschool's observations to the doctor in check-ups/references.

In the extract, an intertextual description of the doctor's action is provided, and it takes a powerful position in influencing the actions of educators. The binding nature of the description is strengthened by the task assigned to the mother, who is given the responsibility of conveying information between the educators and the doctor. A strong position is particularly typical when specialists are referred to. Parents are seldom allocated this kind of power position. However, regarding children, only a few examples of a child's intertextual voice in a powerful position was found. Extract 17 presents an example where an educator writes about the learning objectives for Ella.

\section{Extract 17}

\section{Learning objectives (autumn 2015)}

Ella: (I would like to) learn to read.

\section{Assessment (spring 2016)}


Ella's own objective concerning learning to read has progressed with small steps so that she knows syllables when saying them out loud. Motivation has been swinging up and down.

In Extract 17, the educator describes Ella's desire to learn to read with an indirect quotation and sets this as a specific learning objective for Ella. This kind of usage of a child's perspective seems rare, even though children's desires about the content of their education, such as learning to read, are often recorded. Furthermore, Ella's educator revisits the objective later, when the fulfillment of the IEP is evaluated. Therefore, the objective Ella presented seems to be binding to the educator's work, and consequently, Ella is in the position of a powerful decision-maker.

In addition to adding content, assigning the responsibility to others can mean that they can restrict or forbid certain matters. This kind of use of intertextual voice solely concerned parents. The matters that educators constructed as dependent on parental approval included: 1) content of education (religion, the use of information technology, and popular culture); 2) everyday routine events (sleeping during nap time, excursions); and 3) arrangements of educational support (providing support, asking for a referral for an examination or consultation, transferring information). In Extracts 18 and 19, an intertextual parental voice authorizes educators to support the child.

\section{Extract 18}

Guardians' position to support is affirmative.

\section{Extract 19}

We discussed a possible examination period in a central hospital with the father. Mia Niemi (the psychologist) could do the referral. Father will think about it ... 
In Extract 18, the educator describes a parental consent. The affirmation is presented in a very formal manner with legal terms. Parents are constructed as having an influence on the decision about their child's support, yet how this is actualized is not described. This kind of sentence about parental approval is typical in the IEPs of children who are identified as having SEN. Sometimes, parents are given an even more predominant power position, as in Extract 19, where the father has the last word in arranging a more detailed examination concerning SEN. In the extract, the father is described as a gate-keeper in the process of inspecting SEN in health care. The father's hesitation about the permission is described and, as a result, the situation seems stagnant as the father has to make up his mind. Simultaneously, the writer shows her stance toward the father's decision by using an ellipsis at the end of the description, which can be seen as a marker of an uncompleted issue or disagreement. However, the father seems to have the final word; his opinion is constructed as pre-conditional to the educators' actions, which is in line with parents' legislative right to make decisions about their child's medical and psychological examinations.

\section{Discussion}

In this study, we investigated how the voices of children, parents, and specialists were described and used in the IEPs. A contradictory finding in relation to previous research (e.g., Paananen \& Lipponen, 2016; Rosetti et al., 2018) was the higher prevalence of voices of children who are identified as having SEN (22.2\%) and their parents $(33.3 \%)$ compared to children without identified SEN (11.7\%) and their parents (19.7\%). However, even though children and parents had a say in the IEPs, the ways in which they were positioned to have power over the planning of support and education varied. Children were typically positioned as speakers without influence, and their information was mainly for 
diversification. The voices of parents were often used to justify an educator's viewpoints; however, they were still typically positioned as lacking binding power and were, thus, subordinate to an educator's voice. In contrast, the position of specialists was observed as strong because they had power over educational planning. These findings are in line with previous research findings that show the dominance of professional voices in IEPs (e.g., Blackwell \& Rossetti, 2014; Kovanen, 2002). Consequently, this study has illustrated that professionals have stronger ownership of IEPs than children and parents. As the shared decision-making and ownership of the documents has positive effects on children in terms of academic achievement (Barnard-Brak \& Lechtenberger, 2010; Sebastian et al., 2017), children and parents should have stronger positions in IEPs as partners.

Considering the linguistic expressions of intertextuality, children, parents, and specialists were referred to differently. The educators seemed to express the most neutral stance toward the voices of specialists. In addition, the adults were mainly cited in a more indirect manner, compared to children, who were cited with direct quotes. However, especially concerning parents, multi-voiced writing and the extensive use of the passive voice made it difficult to identify the source of the information. This way of obscuring the information source is problematic in IEPs as it leaves unclear for whom responsibilities are attributed.

Even though children's views were recorded, their positions can be seen as an “instrumental call” for participation (Raby, 2014, p. 84), which was also the case for parents, even though they were more often considered valid informants. Thus, although presenting the viewpoints of parents and children in order to create a more varied image of a child's situation is of great importance to a holistic view to planning, children's participation is mainly achieved at a symbolic level by providing ostensible and disconnected acts of participation; real involvement in the plot of the IEP remains out of reach for them (see Skrtic, 2005). Following Hart (1992), this kind of instrumentality is 
non-participation, and in Sinclair's (2004) terms, passive participation. Regarding specialists, the actual sharing of power can be identified as they are often cited in IEPs. Consequently, their strong role strengthens the professional dominance in IEPs.

The dominance of professional voices and the instrumental use of especially children's voices can be seen as genre conventions (Koskela, 2013; Linell, 1992) in the writing of IEPs in Finnish ECEC. However, it is important to see that professional dominance is, to some extent, inevitable as IEPs are legal records that educators are obligated to draft. Moreover, the importance of information from specialists has a predominant position when a child has been identified as having SEN. Despite this, as Finnish legislation and regulations explicitly require multiple viewpoints and the participation of both children and parents, there seems to be a discrepancy between policy and practice in writing IEPs.

\section{Limitations and Future Research}

A prime limitation of this study is that the sampling and the research context may limit the transferability of the present findings. The sample size was relatively small, as the data included the IEPs of 108 children. Moreover, even though the data had been collected from five Finnish municipalities and 23 preprimary education classes, it is unlikely that all of the variances in drafting the IEPs are included in the data. The applied purposeful group characteristics sampling, which increased the portion of children who are identified as having SEN in the data, might also have led to a bias.

We chose to apply the ideas of intertextuality and intertextual references when analyzing participation. Consequently, the results concerned participation as it is recorded in IEPs, which cannot be equated with actual participation in interactions. It is possible that children and parents have had a say and have been in influential positions in interactions, discussions, and daily life events in ECEC. Moreover, also utilizing other forms of ECEC 
documentation, especially Reggio-inspired pedagogical documentation (see, e.g., Buldu, 2010; Carr \& Lee, 2012; Mallaguzzi, 1993; Rinaldi, 1993), as research data would probably have illustrated a different picture of children's and parents' participation. In the future, it would be useful to investigate the participation in a more complete manner by including also other forms of pedagogical documentation as well as the discussions related to the IEPs.

\section{Conclusions}

Based on the results of this study, profound reflection on the ways to enhance the multivoiced planning in IEPs is needed. As an example, educators often assess the validity of children's viewpoints by, for example, bringing a critical or amused stance to the description of the child's perspective. However, according to Hart (1992), respecting children's viewpoints is a prerequisite for participation. Thus, it is important that children's viewpoints as well as those of parents are presented in the IEPs. To this end, the importance of a functional IEP form is central as it will set a starting point for writing. In an IEP form, both a section for the children's and parental viewpoints as well as questions directed toward utilizing them are important. Based on the studied IEPs, this is not always the case even though in the majority of the document forms, sections for the child's and the parents' viewpoints were included. In writing an IEP, participation can be enhanced, for example, by referring directly to the child's viewpoint (see also Schryer et al., 2011). Numerous studies have reported the benefits of participatory interventions in enhancing child and parental participation (see, e.g., Jozwik, Cahill, \& Sánchez, 2017; Mueller \& Vick, 2018; Royer, 2017); thus, providing educators with appropriate training could also be considered. 
Especially in the case of children who are identified of having SEN, assisting them with expressing their voice is vital in order to achieve equal opportunities for participation (see also Norwich, Kelly, \& Educational Psychologists in Training, 2006). To achieve this, educators need to have multiple methods that emphasize bodily and other expressions of a child's perspective in addition to written and spoken ones, while also employing augmentative and alternative communication techniques (see also Åmot \& Ytterhus, 2014; Komulainen, 2007). In the IEPs we analyzed, the majority of the parents with immigrant backgrounds or Finnish as their second language had no recorded voice in the documents. This was also the case for the children with the most profound disabilities. Therefore, it is of great importance to find efficient means to access children's and parents' voices irrespective of their language and means of communication. This requires a broad understanding of both participation and the ability to have a say as socially-produced phenomena instead of being something that a person either manages or fails to manage (see Komulainen, 2007). Consequently, it is important to comprehend that professionals play a central role in making participation possible for all individuals and that they can also restrain that from happening.

\section{References}

Aikhenvald, A. Y. (2007). Information source and evidentiality: What can we conclude? Rivista di Linguistica, 19(1), 209-227.

Alasuutari, M. (2014). Voicing the child? A case study in Finnish early childhood education. Childhood, 21(2), 242-259. Doi: 10.1177/0907568213490205

Alasuutari, M., Markström, A. -M., \& Vallberg-Roth, A. -C. (2014). Assessment and documentation in early childhood education. London: Routledge. 
Åmot, I., \& Ytterhus, B. (2014). ‘Talking bodies': Power and counter-power between children and adults in day care. Childhood, 21(2), 260-273. Doi: $10.1177 / 0907568213490971$

Arivett, D. L., Rust, J. O., Brissie, J. S., \& Dansby, V. S (2007). Special education teachers' perceptions of school psychologists in the context of individualized education program meetings. Education, 127(3), 378-388.

Bakhtin, M.M. (1981). The dialogic imagination: Four essays by M. M. Bakhtin (C. Emerson \& M. Holquist, Trans.). Austin: University of Texas Press.

Barnard-Brak, L., \& Lechtenberger, D. (2010). Student IEP participation and academic achievement across time. Remedial and Special Education, 31 (5), 343-349. Doi: $10.1177 / 0741932509338382$

Barnes, K. J., \& Turner, K. D. (2001). Team collaboration practices between teachers and occupational therapists. American Journal of Occupational Therapy, 55(1), 83-89. Doi: 10.5014/ajot.55.1.83

Basic Education Act 628/1998. Retrieved from https://www.finlex.fi/fi/laki/ajantasa/1998/19980628

Bayat, M., Mindes, G., \& Covitt, S. (2010). What does RTI (Response to Intervention) look like in preschool? Early Childhood Education Journal, 37, 493-500. Doi: $10.1007 / \mathrm{s} 10643-010-0372-6$

Bednarek, M. (2006). Epistemological positioning and evidentiality in English news discourse: A text-driven approach. Text \& Talk 26(6), 635-660. Doi: 10.1515/TEXT.2006.027

Blackwell, W. H., \& Rossetti, Z. S. (2014). The development of individualized education programs: Where have we been and where should we go now? Sage Open, 1-15. Doi: $10.1177 / 2158244014530411$ 
Buldu, M. (2010). Making learning visible in kindergarten classrooms: Pedagogical documentation as a formative assessment technique. Teaching and Teacher Education, 26(7), 1439-1449. Doi: 10.1016/j.tate.2010.05.003

Carr, M., \& Lee, W. (2012). Learning Stories: Constructing Learner Identities in Early Education. London: Sage.

Christians, C. G. (2011). Ethics and politics in qualitative research. In N. K. Denzin \& Y. S. Lincoln (Eds.), The Sage handbook of qualitative research (4th ed.) (pp. 61-80). Thousand Oaks: Sage.

Clark, H. \& Gerrig, R. J. (1990). Quotations as demonstrations. Language, 66(4), 764-805. Doi: $10.2307 / 414729$

Daniels, H. (2006). The dangers of corruption in special needs education. British Journal of Special Education, 33(1), 4-9. Doi: 10.1111/j.1467-8578.2006.00405.x

Early Childhood Education Act 540/2018. Retrieved from https://www.finlex.fi/fi/laki/ajantasa/2018/20180540?search\%5Btype\%5D=pika\&sea rch\%5Bpika\%5D=varhaiskasvatuslaki

Epstein, J. L. (1995). School/family/community partnerships: Caring for the children we share. Phi Delta Kappa, 76(9), 701-712. Doi: 10.1177/003172171009200326

Elfström Pettersson, K. (2015). Children's participation in preschool documentation practices. Childhood, 22(2), 231-247. Doi: 10.1177/0907568213513480

Fairclough, N. (1992a). Intertextuality in critical discourse analysis. Linguistics and Education 4, 269-293.

Fairclough, N. (1992b). Discourse and social change. Cambridge: Polity Press. Fairclough, N. (2003). Analysing discourse: Textual analysis for social research. New York: Routledge. 
Fish, W. W. (2008). The IEP meeting: Perceptions of parents of students who receive special education services. Preventing School Failure, 52(1), 8-14. Doi:

10.3200/PSFL.53.1.8-14

FNBE (Finnish National Board of Education). (2016). National core curriculum for preprimary education. Regulations and guidelines 2016: 6.

FNBE (Finnish National Board of Education). (2017). National core curriculum for early childhood education. Regulations and guidelines 2017: 10.

Forbes, J. (2008). Knowledge transformations: Examining the knowledge needed in teacher and speech and language therapist co-work. Educational Review, 60(2), 141154. Doi: $10.1080 / 00131910801933989$

Gallagher, M. (2008). Foucault, power and participation. International Journal of Children's Rights, 16(3), 395-406. Doi: 10.1163/157181808X311222

Goepel, J. (2009). Constructing the individual education plan: Confusion or collaboration? Support for Learning, 24(3), 126-132. Doi: 10.1111/j.1467-9604.2009.01412.x

Günther, K., Raitakari, S., \& Juhila, K. (2015). From plan meetings to care plans: Genre chains and the intertextual relations of text and talk. Discourse \& Communication 9(1), 65-79. Doi: 10.1177/1750481314555265

Hart, R. A. (1992). Children's participation. From tokenism to citizenship. UNICEF: Florence. Retrieved from https://www.unicefirc.org/publications/pdf/childrens_participation.pdf

Hill, M., Davis, J., Prout, A., \& Tisdall, K. (2004). Moving the participation agenda forward. Children \& Society, 18(2), 77-96. Doi: 10.1002/chi.819

Hodge, N., \& Runswick-Cole, K. (2008). Problematising parent-professional partnerships in education. Disability \& Society, 23(6), 637-647. Doi:

$10.1080 / 09687590802328543$ 
Horgan, D., Forde, C., Martin, S., \& Parkes, A. (2017). Children's participation: Moving from the performative to the social. Children's Geographies, 15(3), 274-288. Doi: $10.1080 / 14733285.2016 .1219022$

Isaksson, J. (2007). School problems or individual shortcomings? A study of individual educational plans in Sweden. European Journal of Special Needs Education, 22(1), 75-91. Doi: 10.1080/08856250601082323

Jozwik, S. L., Cahill, A., \& Sánchez, G. (2017). Collaboratively crafting individualized education program goals for culturally and linguistically diverse students. Preventing School Failure: Alternative Education for Children and Youth, 62(2), 140-148. Doi: 10.1080/1045988X.2017.1393791

Kamberelis, G., \& Scott, K. D. (1992). Other people's voices: The coarticulation of texts and subjectivities. Linguistics and Education 4, 359-403. Doi: 10.1016/08985898(92)90008-K

Karila, K. (2006). The significance of parent-practitioner interaction in early childhood education. Zeitschrift für qualitative Bildungs-, Beratungs- und Sozialforschung, $7(1), 7-24$.

Karila, K., \& Alasuutari, M. (2012). Drawing partnership on paper: How do the forms for individual education plans frame parent - teacher relationship? International Journal about Parents in Education, 6(1), 15-27. Retrieved from http://www.ernape.net/ejournal/index.php/IJPE/article/view/186/124

Karlsdottir, K., \& Garoarsdottir, B. (2010). Exploring children's learning stories as an assessment method for research and practice. Early Years, 30(3), 255-266. Doi: $10.1080 / 09575146.2010 .506431$

Kelle, H., Seehaus, R., \& Bollig, S. (2015). Child health records as socio-material instruments of distributing responsibility. A comparative analysis of paediatric 
documents from Austria, England and Germany. Children \& Society, 29(3), 184 197. Doi: $10.1111 /$ chso. 12109

Komter, M. L. (2006). From talk to text: The interactional construction of a police record. Research on Language and Social Interaction 39(3), 201-228. Doi: 10.1207/s15327973rlsi3903_2

Komulainen, S. (2007). The ambiguity of the child's 'voice' in social research. Childhood, 14(1), 11-28. Doi: 10.1177/0907568207068561

Koskela, M. (2013). Same, same, but different: Intertextual and interdiscursive features of communication strategy texts. Discourse \& Communication, 7(4), 389-407. Doi: $10.1177 / 1750481313498655$

Kovanen, P. (2002). Reaching towards individualization in planning for children with special needs. Scandinavian Journal of Disability Research, 4(2), 190-202. Doi: $10.1080 / 15017410209510791$

Lansdown, G. (2005). Can you hear me? The right of young children to participate in decisions affecting them. Working Papers in Early Childhood Development, 36. Hague: Bernard Van Leer Foundation. Retrieved from https://files.eric.ed.gov/fulltext/ED522740.pdf

Linell, P. (1998). Discourse across boundaries: On recontextualizations and the blending of voices in professional discourse. Text, 18(2), 142-157. Doi:

10.1515/text.1.1998.18.2.143

Malaguzzi, L. (1993). History, ideas, and basic philosophy. An interview with Lella Gandini. In C. Edwards, L. Gandini, G. Forman (Eds.), The hundred languages of children: The Reggio Emilia approach to early childhood education (pp. 49-97). Norwood, New Jersey: Ablex. 
Markström, A.-M. (2015). Children's views of documentation in the relations between home and school. Children \& Society, 29(3), 231-241. Doi: 10.1111/chso.12114

Martin, J. E., Huber Marshall, L., \& Sale, P. (2004). A 3-year study of middle, junior high, and high school IEP meetings. Exceptional Children, 70(3), 285-297. Doi:

$10.1177 / 001440290407000302$

Mayes, P. (1990). Quotation in spoken English. Studies in Language, 14(2), 325-363. Doi: 10.1075/sl.14.2.04may

Mueller, T. G., \& Vick, A. M. (2018). Rebuilding the family-professional partnership through facilitated individual education program meetings: A conflict prevention and resolution practice. Journal of Educational and Psychological Consultation. Doi: $10.1080 / 10474412.2018 .1470934$

National Institute for Health and Welfare (NIHW). (2017). Varhaiskasvatus 2016 Kuntakyselyn osaraportti [Early childhood education and care 2016 - Part report of municipal survey]. NIHW. Retrieved from http://www.julkari.fi/handle/10024/135184

Norwich, B., Kelly, N., \& Educational Psychologists in Training. (2006). Evaluating children's participation in SEN procedures: Lessons for educational psychologists. Educational Psychology in Practice, 22(3), 255-271.

NRDCWH (National Research and Development Centre for Welfare and Health). (2003). National curriculum guidelines on early childhood education and care in Finland. Retrieved from http://www.julkari.fi/bitstream/handle/10024/75535/267671cb-0ec04039-b97b-7ac6ce6b9c10.pdf?sequence=1

Paananen, P., \& Lipponen, L. (2016). Pedagogical documentation as a lens for examining equality in early childhood education. Early Child Development and Care, 188(2), 77-87. Doi: 10.1080/03004430.2016.1241777 
Pang, Y. (2011). Barriers and solutions in involving culturally linguistically diverse families in the IFSP/IEP process. Making Connections: Interdisciplinary Approaches to Cultural Diversity, 12(2), 42-51.

Patton, M. Q. (2015). Qualitative research \& evaluation methods (4th ed.). Los Angeles: Sage.

Raby, R. (2014). Children's participation as neo-liberal governance? Discourse: Studies in the Cultural Politics of Education, 35(1), 77-89. Doi:

$10.1080 / 01596306.2012 .739468$

Rantala, A., Uotinen, S., \& McWilliam, R. A. (2009). Providing early intervention within natural environments: A cross-cultural comparison. Infants \& Young Children, 22(2), 119-131. Doi: 10.1097/IYC.0b013e3181a02f98

Ravotas, D., \& Berkenkotter, C. (1998). Voices in the texts: The uses of reported speech in a psychotherapist's notes and initial assessments. Text, 18(2), 211-239. Doi: 10.1515/text.1.1998.18.2.211

Reiman, J. W., Beck, L., Coppola, T., \& Engiles, J. D. (2010). Parents' experiences with the IEP process: Considerations for improving practice. Center for Appropriate Dispute Resolution in Special Education (CADRE). Retrieved from https://files.eric.ed.gov/fulltext/ED512611.pdf

Rinaldi, C. (1993). The emergent curriculum and social constructivism. In C. Edwards, L. Gandini, \& G. Forman (Eds.), The hundred languages of children: The Reggio Emilia approach to early childhood education (pp. 101-111). Norwood, New Jersey: Ablex,

Røn Larsen, M. (2016). 'May I please tell you a little anecdote?' Inter-professional decision-making about inclusion in the borderland between general and special 
schooling. International Journal of School Disaffection, 12(1), 65-84. Doi: 10.18546/IJSD.12.1.04

Rossetti, Z., Redash, A., Sauer, J. S., Bui, O., Wen, Y., \& Regensburger, D. (2018). Access, accountability, and advocacy: Culturally and linguistically diverse families' participation in IEP meetings. Exceptionality. Doi: 10.1080/09362835.2018.1480948

Royer, D. J. (2017). My IEP: A student-directed individual education program model. Exceptionality, 25(4), 235-252. Doi: 10.1080/09362835.2016.1216850

Ruppar, A. L., \& Gaffney, J. S. (2011). Individualized education program team decisions: A preliminary study of conversations, negotiations, and power. Research \& Practice for Persons with Severe Disabilities, 36, 11-22. Doi: 10.2511/rpsd.36.1-2.11

Sandall, S., McLean, M. E., \& Smith, B. J. (2000). DEC recommended practices in early intervention/early childhood special education. Longmont, CO: Sopris West. Retrieved from https://files.eric.ed.gov/fulltext/ED451662.pdf

Schryer, C., Bell, S., Mian, M., Spafford, M. M., \& Lingard, L. (2011). Professional citation practices in child maltreatment forensic letters. Written Communication, 28(2), 147-171. Doi: 10.1177/0741088311399710

Sebastian, J., Moon, J. - M., \& Gunningham, M., (2017). The Relationship of schoolbased parental involvement with student achievement: A comparison of principal and parent survey reports from PISA 2012. Educational Studies 43 (2), 123-146. Doi: $10.1080 / 03055698.2016 .1248900$

Shier, H. (2001). Pathways to participation: Openings, opportunities and obligations. Children \& Society, 15(2), 107-117. Doi: 10.1002/chi.617

Sinclair, R. (2004). Participation in practice: making it meaningful, effective and sustainable. Children \& Society, 18(2), 106-118. Doi: 10.1002/chi.817 
Skrtic, T. M. (2005). A political economy of learning disability. Learning Disabilities Quarterly, 28(2), 149-155. Doi: 10.2307/1593616

Slade, N., Eisenhower, A., Carter, A. S., \& Blacher, J. (2018). Satisfaction with individualized education programs among parents of young children with ASD. Exceptional Children, 84(3), 242-260. Doi: 10.1177/0014402917742923

Thomas, N. (2007). Towards a theory of children's participation. The International Journal of Children's Rights, 15(2), 199-218. Doi: 10.1163/092755607X206489

Trivette, C. M., \& Dunst, C. J. (2000). Recommended practices in family-based practices. In S. Sandall, M. McLean, \& B. Smith (Eds.), DEC recommended practices in early intervention/early childhood special education (pp. 39-46). Retrieved from https://archive.org/details/ERIC_ED451662

Warren, S. R. (2017). Hidden voices: Parents' perspectives on the barriers to and facilitators of inclusion on their preschool children with disabilities. In K. Scorgie \& D. Sobsey (Eds.), Working with families for inclusive education (International Perspectives on Inclusive Education, Volume 10) (pp. 151-174). Bingley, UK: Emerald Publishing Limited.

Zeitlin, V. M., \& Curcic, S. (2014). Parental voices on individual education programs: 'Oh, IEP meeting tomorrow? Rum tonight!' Disability \& Society, 29(3), 373-387. Doi: $10.1080 / 09687599.2013 .776493$ 
Table 1. The Research Data

Name of the document

$\mathrm{n}(\mathrm{N}=287)$

ECEC plan

Preprimary education plan

100

Support-centered plans

26 
Table 2. The prevalence of the educators' descriptions of intertextual voices in the IEPs

\begin{tabular}{lccc}
\hline & All children & Children with SEN & Children without SEN \\
$\%(\mathrm{~N}=108)$ & $(\mathrm{n}=29)$ & $(\mathrm{n}=79)$ \\
\hline Child's voice & 15.3 & 22.2 & 11.7 \\
Parent's voice & 24.4 & 33.3 & 19.7 \\
Specialists' voice & 15.0 & 31.3 & 6.4 \\
\hline
\end{tabular}


Table 3. The typical markers of intertextuality and other linguistic features of intertextual voices

\begin{tabular}{lll}
\hline Intertextual voice & Typical markers of intertextuality & Other key linguistic features \\
\hline A child & Direct quotations in quotation marks, & Explicit references, interpretive writing \\
& scare quotes, reportative clauses & \\
Parent(s) / guardian(s) & Indirect quotations, reportative clauses & Blending and blurring of voices \\
A specialist & Indirect quotations, reportative clauses, & Explicitness in referencing \\
& single direct quotations & \\
\end{tabular}


Table 4. Linguistic functions of using intertextual information in the text, epistemic position and information types

\begin{tabular}{llll}
\hline No. & Linguistic function of using & Epistemic position of an & The type of information \\
& intertextual information & intertextual voice & \\
\hline 1 & Creating multi-perspective texts & Speaker without influence & Diversifying information \\
2 & Presenting evidence for author's & Legitimator & Confirming information \\
& argumentation & & Binding information \\
& Assigning the responsibility to & Decision-maker &
\end{tabular}

